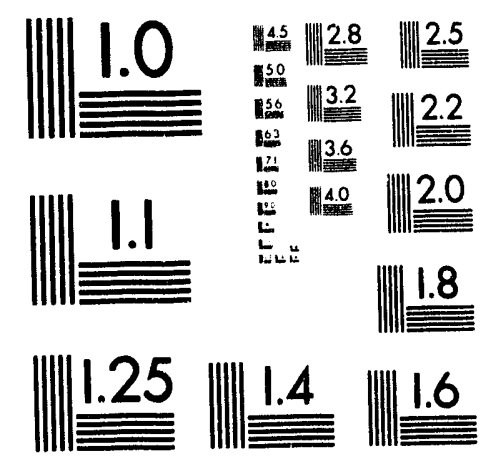



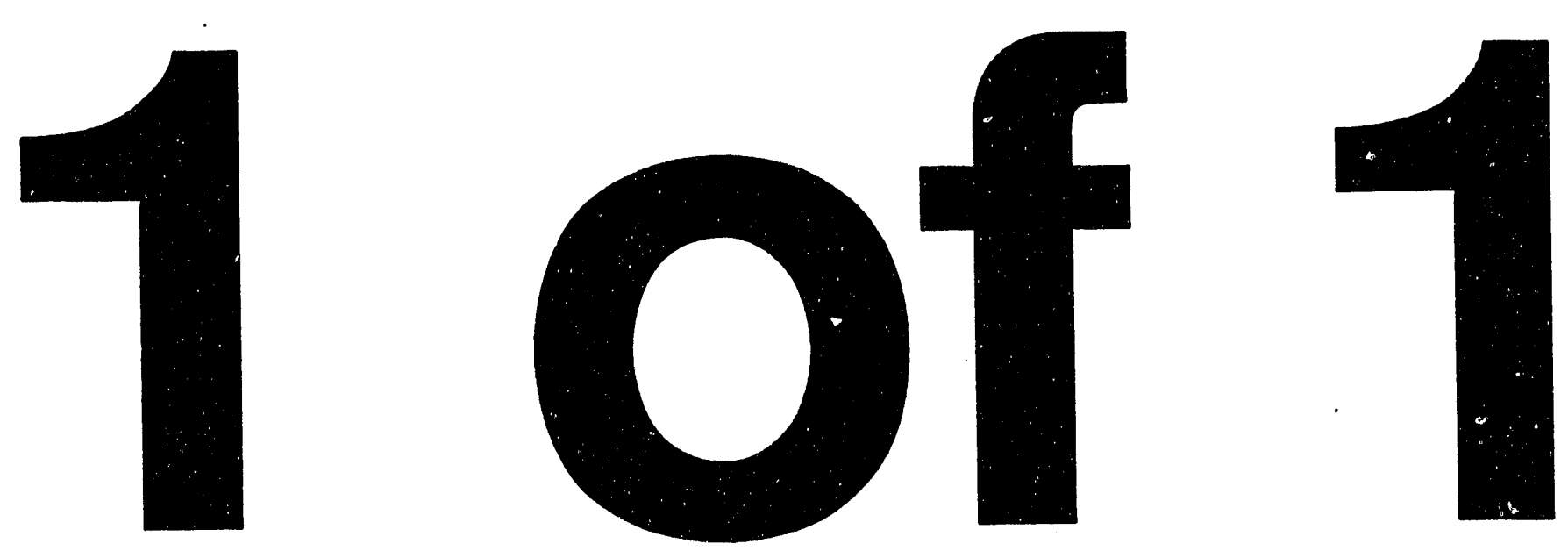


\section{PHOTOCONDUCTIVE SEMICONDUCTOR SWITCHES FOR PULSED POWER APPLICATIONS*}

\author{
G. M. Loubriel, F. J. Zutavern, G. J. Denison, W. D. Helgeson, \\ D. L. McLaughlin, M. W. O'Malley, and M. T. Buttram \\ High Power Electromagnetics Department \\ Sandia National Laboratories \\ Albuquerque, NM 87185 \\ Tel. (505)-845-7096
}

Abstract: Photoconductive Semiconductor Switches (PCSS) are being used in, or tested for, many different pulsed power applications as diverse as ultrawideband (UWB) transmitters and high current pulsers. Some aspects of the switches that are relevant to most of the applications are: switch lifetime (longevity), switch opening time (related to the lifetime of carriers in the semiconductor), switching jitter, and the required laser energy. This paper will emphasize the results that we have obtained with Si switches for UWB applications. These include: measurement of switch longevity ( a total of 80 Coulombs or $40 \mathrm{C} / \mathrm{cm}$ for a $2 \mathrm{~cm}$ wide switch and 18.4 Coulombs or 73 Coulombs $/ \mathrm{cm}$ for a $0.25 \mathrm{~cm}$ wide switch), switching at high repetition rates (up to $540 \mathrm{~Hz}$ ), measurement of carrier lifetime decay rates (a fast one of a few $\mu$ s, and a slow one of about $330 \mu \mathrm{s}$ ), and measurements on the effect of neutron irradiation on carrier lifetimes. The total charge switched seems to be the highest ever reported for a PCSS. We have used these Si switches in a variety of circuits to produce: a monocycle with a period of about $10 \mathrm{~ns}$ corresponding to a center frequency of about $84 \mathrm{MHz}$, and ringing (many pulse) waveforms with periods of about $1 \mathrm{~ns}$ and $7.5 \mathrm{~ns}$ corresponding to center frequencies of $770 \mathrm{MHz}$ and $133 \mathrm{MHz}$. We will also discuss recent studies on the switching properties of $\mathrm{GaP}$.

\section{Introduction}

Photoconductive Semiconductor Switches (PCSS) offer improvements over existing pulsed power technology: higher voltage, higher current, more efficient, faster turn-on, faster turn-off, higher repetition rates, easier control, more precise timing control, more reproducible operation, longer device longevity, smaller size, and lower cost. The most significant possibilities are: $100 \mathrm{ps}$ risetime, kilohertz (continuous) and megahertz (burst) repetition rates, scalable or stackable to hundreds of kilovolts and tens of kiloamps, optical control and isolation, and solid state reliability. The switching properties that have been achieved with our lateral Si (in the linear mode ${ }^{1}$ ) and $\mathrm{GaAs}$ (in the non-linear, high gain switching mode ${ }^{2,3}$ are summarized in Table I. In this paper, we present experimental results

*This work was supported by the U. S. Department of Energy under Contract DE-AC04-76DP00789 and by the U. S. Air Force, Air Force Systems Command, Phillips Laboratory, Kirtland AFB, NM 87117-6008 under prime contract $\overline{\mathrm{F}} 2960 \mathrm{i}-9 \mathrm{i}-\mathrm{C} 00 \mathrm{4} 6$.
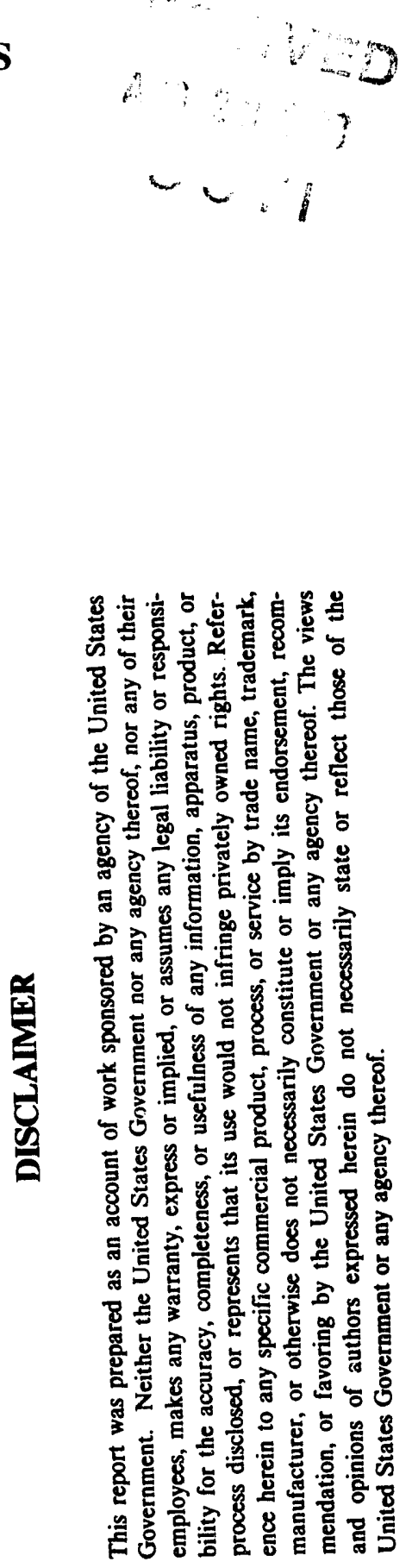

\section{MASTER}


which demonstrate some of these, and other (data on switching GaP), improvements.

The PCSS are being tested for use in applications such as: ultrawideband (UWB) tran'mitters, firing sets, electro-optic drivers, current interrupters, and pulsed power applications that require MV switching. Each of these applications imposes a different set of requirements on switch properties. The sections below emphasize those properties that are related to the generation of fast, high power impulses that are typical of those required for UWB transmitters or fast pulsers.

\section{Si-Linear Switching- High Voltage Operation}

The concept of linear photoconductive semiconductor switching is described in several references ${ }^{1}$. This switching mode is characterized by the creation of one electron- hole pair for nearly every photon absorbed in the semiconductor. Because the resistance of the switch is inversely proportional to the number of carriers, the risetime of the switch is typically proportional to the optical pulse width. This effect was demonstrated ${ }^{4}$ using a 200 ps optical pulse that triggered a Si switch to produce a $270 \mathrm{ps}$ (bandwidth limited by the scopes) current risetime. This same size switch has been used to switch up to $123 \mathrm{kV}$. For $\mathrm{Si}$, our highest switch field and current are $5: 82 \mathrm{kV} / \mathrm{cm}(123 \mathrm{kV})$ and $2.8 \mathrm{kA}$ (not simultaneous). Figure 1 shows the voltage waveforms for the Si PCSS that switched $123 \mathrm{kV}$. This demonstrates that the PCSS can switch high voltages even when using a single device. For impulse transmitters, this voltage limitation is not a barrier that limits the transmitted power because the low jitter of the switches allows for a modular design of transmitter arrays. For more conventional pulsed power applications, the switches can be stacked to switch higher voltages. Nonetheless, the demonstration of MV switching with PCSS has not been carried out, mainly because of the large laser powers required.

\section{Repetitive Switching of Si Switches-Carrier Lifetime}

Another aspect of linear switching that is relevant to pulsed power applications is the ability of the switches to be repetitively switched. After being switched, the semiconductor must recover its original (high) resistivity prior to the application of the next voltage pulse. This implies that the exponential carrier lifetime must be much smaller than the time between pulses. For a typical value of $1 \mathrm{kHz}$, carrier lifetimes of tens of microseconds are required. Carrier lifetime is determined by effects that are intrinsic to the semiconductor and by defects and impurities. We have studied the carrier lifetime of $\mathrm{Si}$ by applying laser pulses and measuring the switch resistance after a known delay. The conductance is given by the inverse of the intrinsic dark resistance $\left(R_{0}\right)$ plus that due to the laser pulse, whose decay in time is exponential. Figure 2 shows $(1 / R)-\left(1 / R_{0}\right)$ as a function of delay time for a silicon switch. There are two slopes: A fast decay of $4.3 \mu \mathrm{s}$ and a slow one of $335 \mu \mathrm{s}$. To understand why there are two 
slcpes, the $\mathrm{Si}$ material was subjected to various neutron bombardment fluences $\left(10^{11}, 10^{12}, 10^{13}\right.$, and $\left.10^{14}\right)$. Figure 3 shows $(1 / R)-\left(1 / R_{0}\right)$ for these switches. The fast decay implies carrier lifetimes of $4.3 \mu \mathrm{s}, 2.6 \mu \mathrm{s}$, $560 \mathrm{~ns}$, and $<<500 \mathrm{~ns}$. We attribute the fast decay to recombination via defects that are created by the neutron bombardment. The slow decay is not affected by the neutron bombardment. Lifetimes of 392,319 , and $360 \mu \mathrm{s}$ were measured for fluences of $10^{11}, 10^{12}$, and $10^{13}$. We attribute the slow decay to deep level (impurity) decay because the number of impurities is not affected by the neutron bombardment.

\section{Longevity of Si Switches- Tests of Contact Metallization}

The ability to obtain short carrier lifetime $\mathrm{Si}$ allows the switch to be repetitively triggered. We have been able to trigger the Si switch at a laser limited repetition rate of $540 \mathrm{~Hz}$. Extensive switch lifetime tests have been carried out 6 . Figure 4 shows the electrical circuit used for most of the switch '.fetime tests. The pulsed power source charged a $50 \Omega$ coaxial cable in about $1 \mu \mathrm{s}$. This was discharged by the switch into a $50 \Omega$ load in about $20-30 \mathrm{~ns}$. The system had a switch voltage monitor and a current viewing resistor. Figure 5 shows representative voltage and current waveforms. To trigger the switches we used a Nd:YAG laser that produced $50 \mathrm{~mJ}$ pulses of $10 \mathrm{~ns}$ duration at a repetition rate of $540 \mathrm{~Hz}$. Many different metallizations were tested to determine the wear mechanism and the best contact metallization. The switches wear at the contact metallization, at the interface between the metallization and the Si. For the $\mathrm{Si}$ switches, the current is uniform across the width of our lateral switches. The current density, thus, is the same at either the anode or cathode. Because the wear occurs preferentially at one or the other contact (dependent on the metallization) the wear is not due to an excessive current density in the metal film. We believe that current bunching at the edge of the contact metallization is responsible for the wear. Auger studies show no electromigration of the contact metallization. The Auger data is consistent with heating by elevated, short duration, temperatures at the contact edge which results in vaporization or delamination.

The switches with $\mathrm{Cr}$-Cr-Mo-Au metallization survived $6 \times 10^{6}$ pulses at up to $22 \mathrm{kV} / \mathrm{cm}(5.5 \mathrm{kV})$ and $160 \mathrm{~A} / \mathrm{cm}(40 \mathrm{~A})$. The waveforms for this switching are shown in figure 5 . The total charge switched was about 8.4 Coulombs which corresponds to a charge per unit width of $33.6 \mathrm{C} / \mathrm{cm}$. Figure 6 shows the current waveform for a switch with $\mathrm{Cr}-\mathrm{Cr}-\mathrm{Mo}-\mathrm{Au}$ metallization that had dimensions of $1.5 \mathrm{~cm}$ by $2.0 \mathrm{~cm}$ so that we could switch higher voltages. The switched field was $20 \mathrm{kV} / \mathrm{cm}(30 \mathrm{kV})$, the peak current density was $187 \mathrm{~A} / \mathrm{cm}(375 \mathrm{~A})$. This system had a $50 \Omega$ load so that the power was about $7 \mathrm{MW}$. The total number of pulses on this larger switch was 11 million, so that the total charge switched was about 80 Coulombs $(40 \mathrm{C} / \mathrm{cm})$. Although both of these switches were still running after these pulses, there was severe degradation of the metallization with preferential damage on the positive contact. Severe degradation and similar lifetimes are also observed when thick films (Mo layer of $6500 \mathrm{~A}$ ) are used. 
We have also plated the $\mathrm{Cr}$-Cr-Mo-Au switches to obtain a much thicker $\mathrm{Au}$ film. Again, the results do not differ much from those with the standard $\mathrm{Cr}$ Cr-Mo-Au metallization.

We have tried to eliminate current pinching at the edge of the contacts by using $\mathrm{Al}$ diffusion to create a conducting layer between the metallization and the high resistivity $\mathrm{Si}$. We investigated two types of Al diffused contacts: deposition of a $1 \mu \mathrm{m}$ thick layer of $\mathrm{Al}$, followed by sintering for 20 minutes at $600 \mathrm{C}$, and deposition of $0.1 \mu \mathrm{m}$ of $\mathrm{Al}$, heating at $400 \mathrm{C}$ for 20 minutes. These were covered with $\mathrm{Cr}(500 \mathrm{~A})-\mathrm{Mo}(1500 \mathrm{~A})-\mathrm{Au}(3000 \mathrm{~A})$ as above. The Cr-Mo-Au deposition was made with the rame mask as the Al deposition so that it completely covers the area of the Si wafer that was covered with Al. The $1 \mu$ switches survived $10^{7}$ pulses at $34 \mathrm{kV} / \mathrm{cm}$. Figure 7 shows the voltage and current waveforms. The total charge switched was about $11 \mathrm{C}(44 \mathrm{C} / \mathrm{cm})$. The $0.1 \mu$ switches thick Al metallized switches survived $32 \mathrm{kV} / \mathrm{cm}$ for 2.4 million pulses, $36 \mathrm{kV} / \mathrm{cm}$ for 1.94 million, 40 $\mathrm{kV} / \mathrm{cm}$ for 1.46 million, and only about 100,000 pulses at $44 \mathrm{kV} / \mathrm{cm}$ at which point the switch failed. The total number of Coulombs switched was $9.6(38.4 \mathrm{C} / \mathrm{cm})$. Both the $\mathrm{Al}$ diffused switches fared better than the nondiffused switches. Most of the damage occurs at the negative contact.

Even better results were obtained with an ion implanted contact $(31 \mathrm{P}$ Phosphorous) that was capped with Ti-Pt metallization. The ion implantation of ${ }^{31} \mathrm{P}$ was carried out at $175 \mathrm{keV}$ for a dose of $2 \times 10^{15}$ and at $60 \mathrm{keV}$ for a dose of $1 \times 10^{15}$. The implant was then annealed for twenty minutes at $950 \mathrm{C}$. This resulted in an estimated ion implantation depth of $0.6 \mu \mathrm{m}$, and a dopant density of about $10^{20}$ carriers $/ \mathrm{cm}^{3}$. The annealing is followed by deposition at $300 \mathrm{C}$ of $\mathrm{Ti}-\mathrm{Pt}$ using electron beam evaporation. This switch has now been run at $48 \mathrm{kV} / \mathrm{cm}$ for 0.9 million pulses $(2.1 \mathrm{C}), 44$ $\mathrm{kV} / \mathrm{cm}$ for 2.2 million pulses, and at $32 \mathrm{kV} / \mathrm{cm}$ for $10^{7}$ pulses $(18.4 \mathrm{C})$. The latter corresponds to $73 \mathrm{C} / \mathrm{cm}$. In the last test the switch was removed before failure and showed only minor damage to the contact. Most of the damage was in the positive contact. Figures 8 and 9 show the voltage and current waveforms for the tests carried out with this switch. The switched voltage was $8.5 \mathrm{kV}(34 \mathrm{kV} / \mathrm{cm})$, and the switch current was $77 \mathrm{~A}(308$ $\mathrm{A} / \mathrm{cm}$ ) which lasted for about $27 \mathrm{~ns}$.

The Ti-Pt metallization in these switches does not cover the total area that is ion implanted. The ion implanted region extends $0.05 \mathrm{~mm}$ beyond the TiPt. The damage observed after $10^{7}$ pulse at $32 \mathrm{kV} / \mathrm{cm}$ is mostly in one corner of the positive contact where there is damage in the metallization and at the interface of the $\mathrm{Si}$ and ion implanted regions. There is almost no damage in the $0.05 \mathrm{~mm}$ of the ion implanted region. It is not clear why there is damage at the interface between the $\mathrm{Si}$ and the ion implanted region. The degree of current bunching there depends on the ratio of the resistivities. No current bunching with be observed if the conductivity of the ion implanted layer is lower than that created by the light in the semiconductor. We estimate that the density of photo-generated carriers in this experiment is about $5 \times 10^{19} \mathrm{~cm}^{3}$. Thus, the carrier density generated 
by the light is about the same as that in the P-doped region and there should be little or no current bunching if the carrier mobilities are the same. The ion implanted region may have lower mobility due to damage.

The metallizations that were described above involved the deposition of the dopants and metal on one face of a Si wafer. The depth of the contact is determined by the diffusion or implantation parameters. Because the penetration of the Nd:YAG radiation is larger than the typical wafer thickness (from 254 to $635 \mu \mathrm{m}$ ), it would be preferable to dope throughout the thickness, eliminating current pinching. One way to achieve this is to cleave the wafer and metallize the edges. We have attempted to fabricate and test this "edge contact" using Cr-Cr-Mo-Au metallization. Several practical problems have arisen. First, that the metallization always tends to coat the edge and about $0.5 \mathrm{~mm}$ of the surface. Second, edges are not uniform so that the metallization tends to be uneven. Third, that it is hard to make good electrical contact to the edge because the switches are fragile. We are still pursuing this promising method.

The mechanisms that may result in damage to the PCSS are many. Initiation of the final breakdown appears to come from regions near the contacts which have been significantly damaged during previous pulses. Contact damage may be caused by large electric potential barriers at the metal-semiconductor interface, high current densities due to current pinching or filaments, and gradual degradation of the interface due to elevated instantaneous temperatures. $\mathrm{Cr}$ and $\mathrm{P}$ are donors to $\mathrm{Si}$ ( $\mathrm{n}$ type) and $\mathrm{Al}$ is an acceptor (p-type). The damage to the $\mathrm{Cr}$. diffused and the ion implanted $\mathrm{P}$ switches is mostly on the positive contact (independent of whether the positive lead is at high voltage or ground) while the Al diffused switches (either the Al-Cr-Mo-Au or the Al-Pt-Ti-Pd-Au) show most damage on the negative contact. This would imply that the damage occurs most often at the reversed biased contact. It does not really explain the nature of the damage. The Auger data and the correlation of damage with type of contact imply that the damage occurs from local heating at the semiconductor-metal interface.

Table I summarizes the Si switch longevity tests. These switches are capable of switching a total of about 70 coulombs per centimeter of width for fields of $32 \mathrm{kV} / \mathrm{cm}(8 \mathrm{kV})$. As the field is increased, the total charge per unit width is reduced by an order of magnitude. It is not clear that the best way to judge a given PCSS is to compare their total current carrying capability. Joule heating of the semiconductor is the product of the switch resistance, the square of the current, and the duration of the pulse. But the damage is not in the semiconductor. Since the damage occurs at the metal semiconductor interface, it may be due to heating produced in a Schottky barrier. In this case, the amount of instantaneous heat is the product of the voltage in the barrier, the current, and the pulse duration. 
Table I. Summary of tests of the longevity of Si switches

$\begin{array}{ccccc}\text { Contact Type } & \mathrm{V}(\mathrm{kV}), \mathrm{I}(\mathrm{A}) & \begin{array}{c}\text { Total number of } \\ \text { pulses (millions) }\end{array} & \begin{array}{c}\text { Total Switched } \\ \text { Charge }(\mathrm{C})\end{array} & \begin{array}{c}\text { Charge / Switch } \\ \text { Width (C/cm) }\end{array} \\ \text { Cr-Cr-Mo-Au } & 5.5,40 & 6 & 8.4 & 34 \\ \text { Cr-Cr-Mo-Au } & 30.0,375 & 11 & 80 & 40 \\ 1.0 \mu \mathrm{Al}, \mathrm{CrMoAu} & 8.5,77 & 10 & 11 & 44 \\ 0.1 \mu \mathrm{Al}, \mathrm{CrMoAu} & 8-11,62-88 & 5.8 & 9.6 & 38 \\ \text { ion implanted P } & 8,68 & 10 & 18.4 & 73 \\ \text { ion implanted P } & 12,96 & 0.9 & 2 & 8\end{array}$

\section{Generation of Ringing Waveforms with Si Switches}

Linear switches have been used to produce current waveforms of high frequency and of varying bandwidth. Figures 10 to 12 show load voltage waveforms for a variety of systems that exhibit different ringing periods (10 ns, $7.5 \mathrm{~ns}$, and $1 \mathrm{~ns}$ ) corresponding to center frequencies of $84 \mathrm{MHz}$, $133 \mathrm{MHz}$, and $770 \mathrm{MHz}$. The $84 \mathrm{MHz}$ data shows a monocycle voltage pulse with high bandwidth. The data at $133 \mathrm{MHz}$ and $770 \mathrm{MHz}$ show that the switches can be used in high frequency ringing systems with high $\mathrm{Q}$.

\section{Switching Properties of GaP}

At low fields, GaAs exhibits linear switching with a carrier lifetime of a few nanoseconds. Above $8 \mathrm{kV} / \mathrm{cm}$, non-linear switching was observed ${ }^{3}$. This non-linear, high gain, high field switching mechanism can be triggered with small laser energies from laser diode arrays ${ }^{7}$ and does not require uniform light illumination permitting the use of fiber optic triggering8. Since this mechanism exist for GaAs (and InP) but not in $\mathrm{Si}$, we studied $\mathrm{GaP}$. Like $\mathrm{Si}$, it is an indirect bandgap semiconductor. Like GaAs and InP, it is a III-V semiconductor with a large $(2.26 \mathrm{eV}$ or $548 \mathrm{~nm})$ bandgap and a zincblend crystal structure.

At low fields, GaP exhibits linear switching with a surprisingly short carrier lifetime. Figure 13 shows the current waveform for a $0.25 \mathrm{~cm}$ long by 0.25 $\mathrm{cm}$ wide $\mathrm{GaP}$ switch that was triggered with $532 \mathrm{~nm}$ radiation. The voltage is $1.5 \mathrm{kV}$ (field of $6 \mathrm{kV} / \mathrm{cm}$ ) when the laser pulse triggers the switch. The laser pulse has a duration of about $30 \mathrm{~ns}$ and is comprised of multiple peaks. The oscillations current show that the laser pulse generates carriers with a very short lifetime ( $<2 \mathrm{~ns})$. Thus, the current pulse resembles the time profile of the laser pulse. This short carrier lifetime is surprising since indirect bandgap semiconductors should have a long carrier lifetime. This result may imply that the material has many impurities. The voltage waveform shows that in this case, the laser pulse energy was not sufficient to drop the switch voltage to zero. The reason for this is the low carrier mobility in GaP: $110 \mathrm{~cm}^{2} / \mathrm{V} \mathrm{s}$. 
The GaP switches were then tested at ever increasing fields in the hope that a high gain, high field switching mechanism would be found. The highest field we tested at was $11 \mathrm{kV}$. High gain switching was never observed. The lack of a high gain switching mode and the low mobility implies that $\mathrm{GaP}$ is not suitable for most pulsed power switching applications.

\section{Conclusions}

Si switches have been used to switch high voltages ( $123 \mathrm{kV})$, high currents $(2.8 \mathrm{kA})$, at high repetition rates $(540 \mathrm{~Hz}$, laser limited). The carrier lifetime in the switches is composed of two decays rates: a fast one of $4 \mu \mathrm{s}$ and a slow one of about $330 \mu \mathrm{s}$. The fast decay rate can be reduced to $<<$ 500 ns. Tests of switch longevity show that the switches, when operated in the linear mode can switch a total of up to $73 \mathrm{C} / \mathrm{cm}$ at $8 \mathrm{kV}, 68 \mathrm{~A}$, with a pulse duration of $27 \mathrm{~ns}$. For UWB applications we have been able to produce a monocycle with a period of about $10 \mathrm{~ns}$ corresponding to a center frequency of about $84 \mathrm{MHz}$ and a high $\mathrm{Q}$ ringing waveforms with center frequencies of 133 and $770 \mathrm{MHz}$. The switching properties of $\mathrm{GaP}$ were also reported. The material exhibits a very short carrier lifetime $(<2 \mathrm{~ns})$ and does not exhibit high gain switching at fields as high as $44 \mathrm{k} / \mathrm{cm}$. The lack of gain and the low carrier mobility in GaP make this material unsuitable for most pulse power switching applications.

\section{Figure Captions}

Figure 1. The voltage across a Si switch. The switched voltage was 123 $\mathrm{kV}$, corresponding to a field of $82 \mathrm{kV} / \mathrm{cm}$.

Figure 2. Plot of $\mathrm{Si}$ switch resistance versus time. To obtain the carrier lifetime we plotted $(1 / R)-\left(1 / R_{0}\right)$, where $R_{0}$ is the switch resistance in the dark (or long times). There are two components of the carrier lifetime.

Figure 3. The effect of neutron bombardment on the carrier lifetime in $\mathrm{Si}$. The various curves correspond to neutron fluences of 0 (upper curve marked with hexagons), $10^{11}(+), 10^{12}$ (squares), $10^{13}$ (lower curve with hexagons), and $10^{14}$ (diamonds).

Figure 4. The electrical circuit used in the tests of $\mathrm{Si}$ switch longevity included a pulsed power source that charged a $50 \Omega$ cable (10 feet long), a $50 \Omega$ terminating resistor, a voltage monitor, the $\mathrm{Si}$ switch, and a current viewing resistor.

Figure 5. The switch with $\mathrm{Cr}$-Cr-Mo-Au metallization switched a total of $8.4 \mathrm{C}(33.6 \mathrm{C} / \mathrm{cm})$. The peak switched voltage was $5.5 \mathrm{kV}(22 \mathrm{kV} / \mathrm{cm})$ and the current was $40 \mathrm{~A}(160 \mathrm{~A} / \mathrm{cm})$. The voltage, current, and time were recorded at $1 \mathrm{kV} / \mathrm{div}, 10 \mathrm{~A} / \mathrm{div}$, and $50 \mathrm{~ns} / \mathrm{div}$, respectively.

Figure 6. A $1.5 \mathrm{~cm}$ long by $2 \mathrm{~cm}$ wide switch with $\mathrm{Cr}-\mathrm{Cr}-\mathrm{Mo}-\mathrm{Au}$ metallization switched a total of $80 \mathrm{C}(40 \mathrm{C} / \mathrm{cm})$ in 11 million pulses. The 
peak switched voltage was $30 \mathrm{kV}(20 \mathrm{kV} / \mathrm{cm})$ and the current was $375 \mathrm{~A}$ $(187 \mathrm{~A} / \mathrm{cm})$. The current waveform was recorded at $200 \mathrm{~A} / \mathrm{div}$ and 20 ns/div.

Figure 7. A switch with $1 \mu \mathrm{m} \mathrm{Al}$ switched a total of $11 \mathrm{C}(44 \mathrm{C} / \mathrm{cm})$. The peak switched voltage was $8.5 \mathrm{kV}(34 \mathrm{kV} / \mathrm{cm})$ and the current was $77 \mathrm{~A}$ $(308 \mathrm{~A} / \mathrm{cm})$. The voltage, current, and time were recorded at $2 \mathrm{kV} / \mathrm{div}, 20$ $\mathrm{A} / \mathrm{div}$, and $20 \mathrm{~ns} / \mathrm{div}$, respectively.

Figure 8. Voltage waveform for switch lifetime tests carried out with the ion implanted $P$ switch. The scales for the axis are $2.5 \mathrm{kV} / \mathrm{div}$ and 200 $\mathrm{ns} /$ div. The switched voltage was $12.15 \mathrm{kV}(48.8 \mathrm{kV} / \mathrm{cm})$. Prior to switch failure, there was no electrical degradation of the voltage pulse.

Figure 9. Current waveform for switch lifetime tests obtained with the ion implanted $P$ switch and the voltage waveform of Figure 9. The current and time are shown at $20 \mathrm{~A} / \mathrm{div}$ and $20 \mathrm{~ns} / \mathrm{div}$. The switched current was $96.4 \mathrm{~A}$ $(386 \mathrm{~A} / \mathrm{cm})$. The total charge switched in this test was only $2 \mathrm{C}(8 \mathrm{C} / \mathrm{cm}), \mathrm{a}$ similar switch was tested at $8 \mathrm{kV}, 68 \mathrm{~A}$ and switched a total of $18.4 \mathrm{C} \mathrm{(73}$ $\mathrm{C} / \mathrm{cm})$.

Figure 10. The current on the load of a Si PCSS switched line showing the capability of the switches to produce a monocycle pulse with a center frequency of $84 \mathrm{MHz}$. This waveform has a very high bandwidth.

Figure 11. The current on the load of a Si PCSS switched line showing the capability of the switches to produce a 3-cycle waveform with a center frequency of $133 \mathrm{MHz}$.

Figure 12. The current on the load of a Si PCSS switched line showing the capability of the switches to produce a multi-cycle pulse with a center frequency of $770 \mathrm{MHz}$.

Figure 13. Current waveform for a GaP switch. The voltage is shown here at $4 \mathrm{~A} / \mathrm{div}$ and the time axis is $10 \mathrm{~ns} / \mathrm{div}$. The oscillations in the current, and the fact that the current returns to zero implies that the carrier lifetime in the $\mathrm{GaP}$ is $<2$ ns.

1 See Picosecond Optoelectronic Devices, edited by C. H. Lee (Academic Press, New York, 1984), and High Power Optically Activated Solid State Switches, edited by A. Rosen and F. J. Zutavern (Artech House, Boston, 1993)

2 See proceedings from: 6-8th IEEE Pulsed Power Conf., 1987, 1989, 1991; 18 20th IEEE Power Modulator Symp., 1988, 1990, 1992; SPIE Optically Activated Switching I-III, (vol. 1378, 1632, 1873), 1990, 1992, 1993; and special issues in IEEE Trans. Elec. Devices, (vol. 37,38), 1990, 1991. 
3 First reported in: G. M. Loubriel, M. W. O'Malley, and F. J. Zutavern, "Towards Pulsed Power Uses for PCSS: Closing Switches," 6th IEEE Pulsed Power Conference, Arlington, VA, 1987, pp. 145-148.

4 F. Zutavern, \$4. W. O'Malley, M. Buttram, and W. Stygar, "Photoconductive Semiconductor Switching for Pulsed Power Applications," in Proc. 5th IEEE Pulsed Power Conf., Arlington, VA, 1985, pp. 246-249.

5 G. M. Loubriel, M. W. O'Malley, F. J. Zutavern, B. B. McKenzie, W. R. Conley, and H. P. Hjalmarson, "High Current PCSS," 18th IEEE Power Modulator Symposium, Hilton Head, SC, 1988, pp. 312- 317.

6 G. M. Loubriel, F. J. Zutavern, G. J. Denison, W. D. Helgeson, D. L. McLaughlin, M. W. O'Malley, C. H. Sifford, L. C. Beavis, C. H. Seager, A. Rosen, and R. G. Madonna, "Long Lifetime Silicon PCSS," Proc. of SPIE's Optically Activated Switching Conference III, Los Angeles, CA, 1993.

7 G. M. Loubriel, W. D. Helgeson, D. L. McLaughlin, M. W. O'Malley, F. J. Zutavern, A. Rosen, and P. J. Stabile, "Triggering GaAs Lock-on Switches with Laser Disde Arrays," IEEE Transactions Electron. Devices, Vol. 38, 1991, pp 692- 695.

8 F. J. Zutavern, G. M. Loubriel, M. W. O'Malley, W. D. Helgeson, D. L. McLaughlin, an G. J. Denison, "Characteristics of Current Filamentation in High Gain PCSS," in Proc. 20th IEEE Power Mod. Symposium, Myrtle Beach, SC, 1992, p 305-311. 

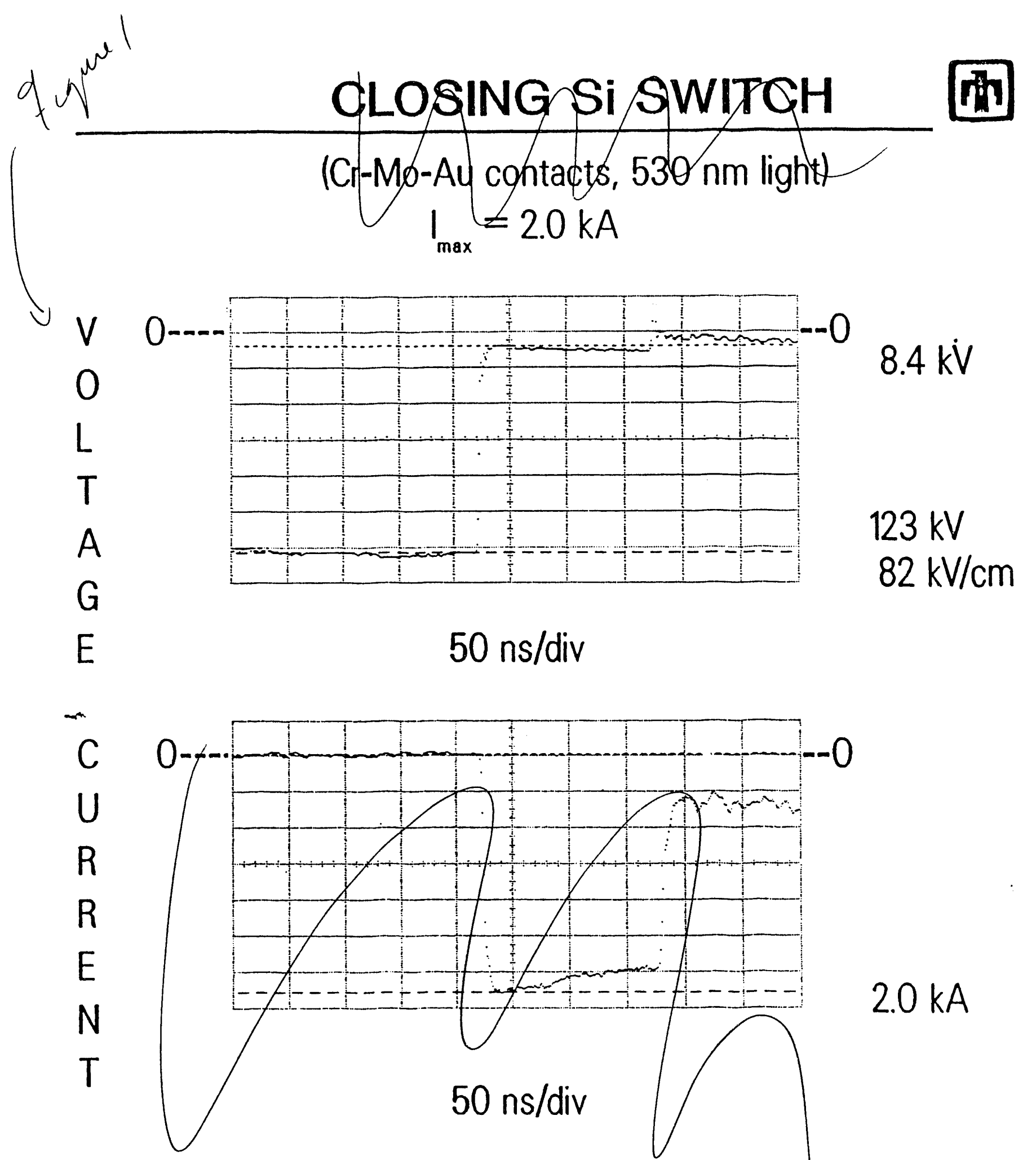

CONCLUSION: Si CAN BE OPERATED AS A CLDSING SWITCH AT FELDS OF $82 \mathrm{kV} / \mathrm{cm}$, AND VOLTAGES OF $123 \mathrm{kV}$. 


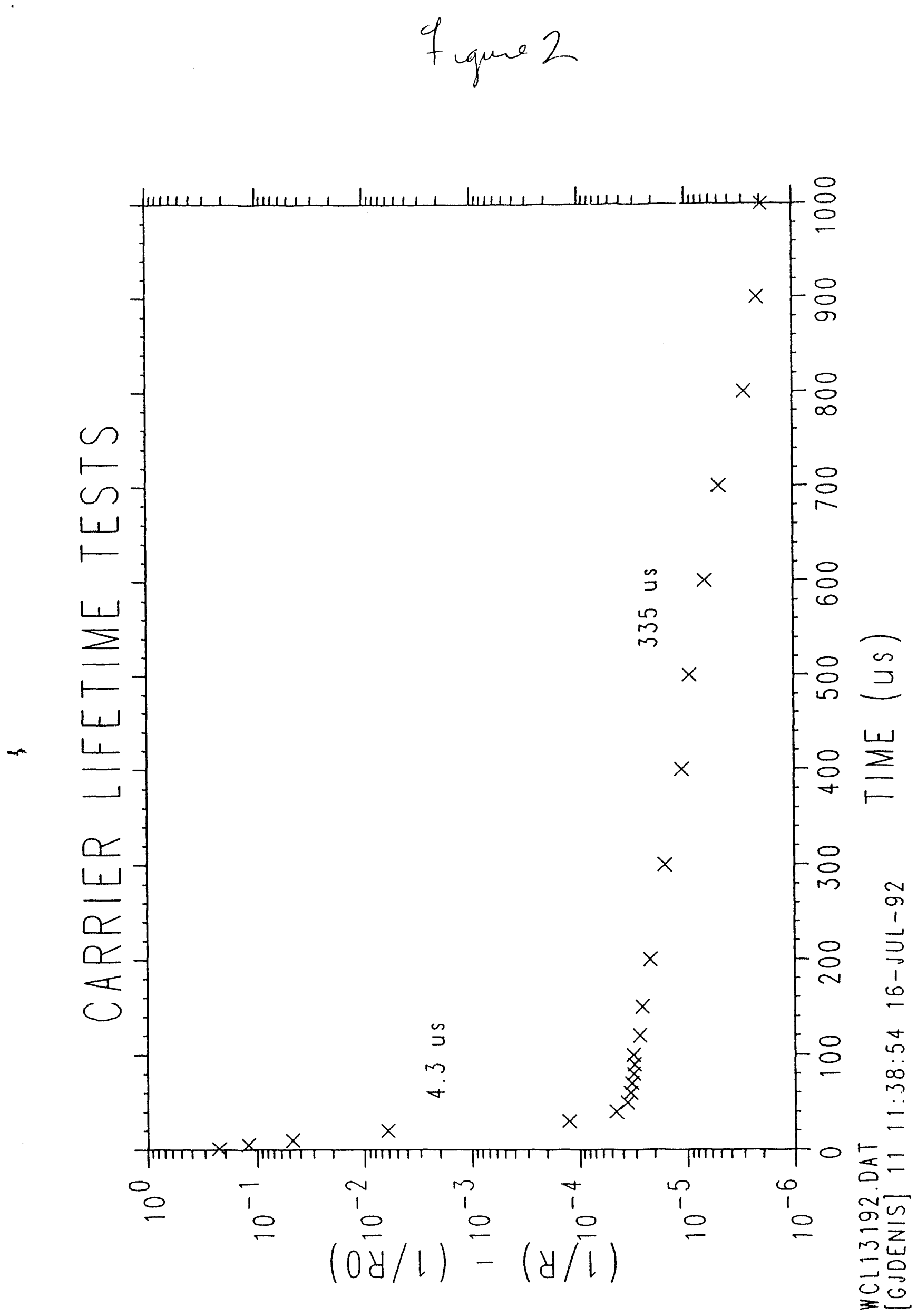

G 


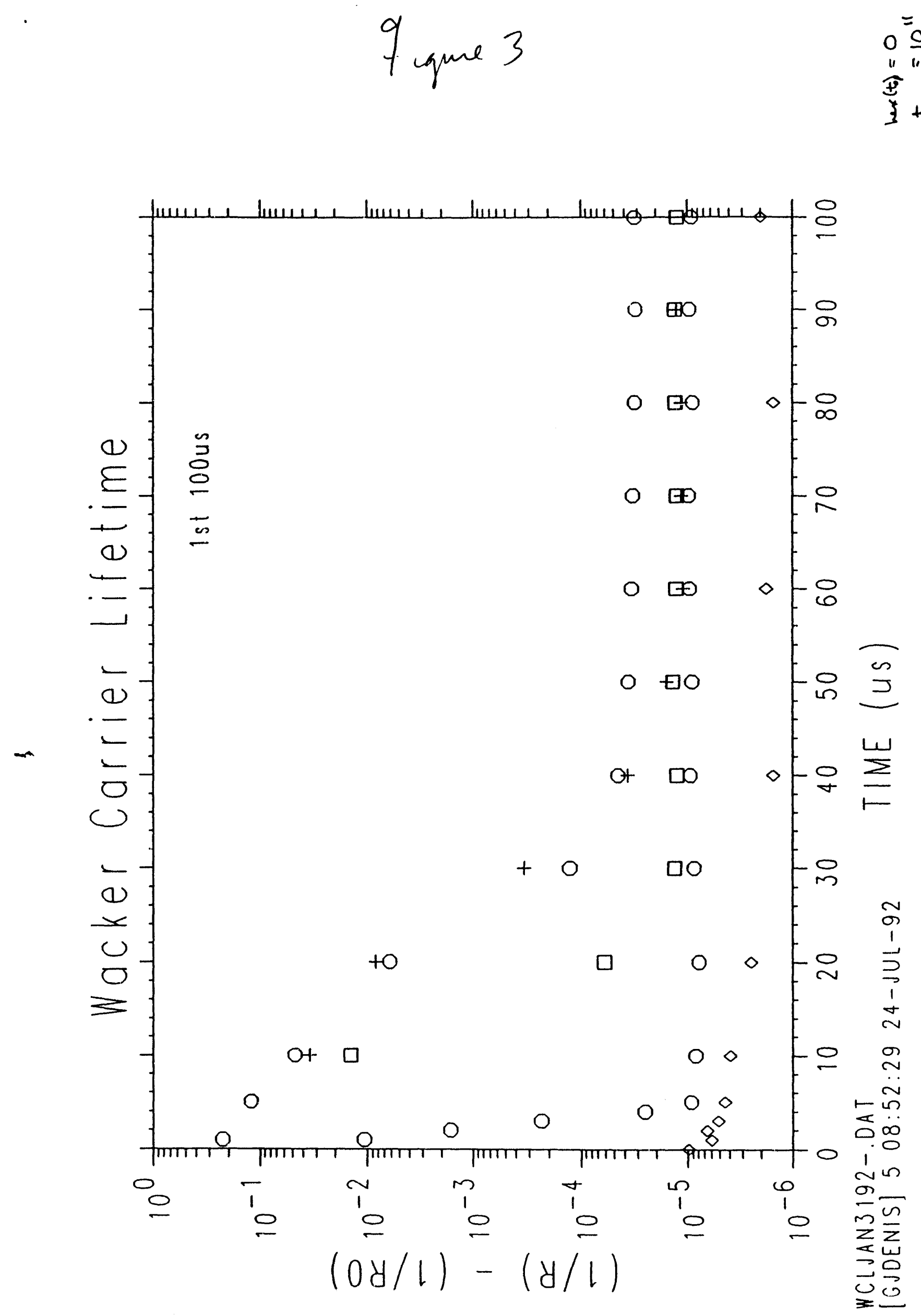




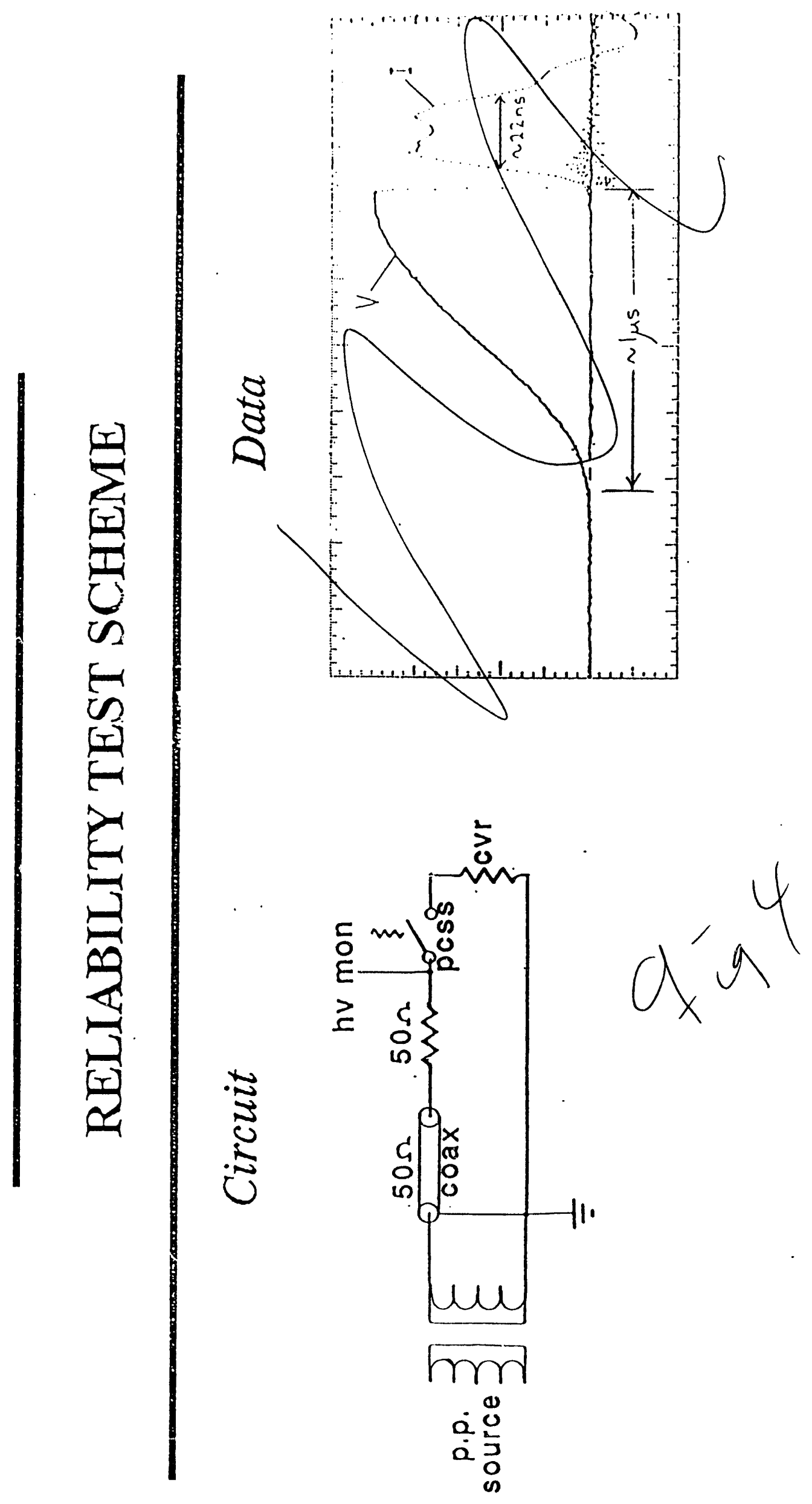




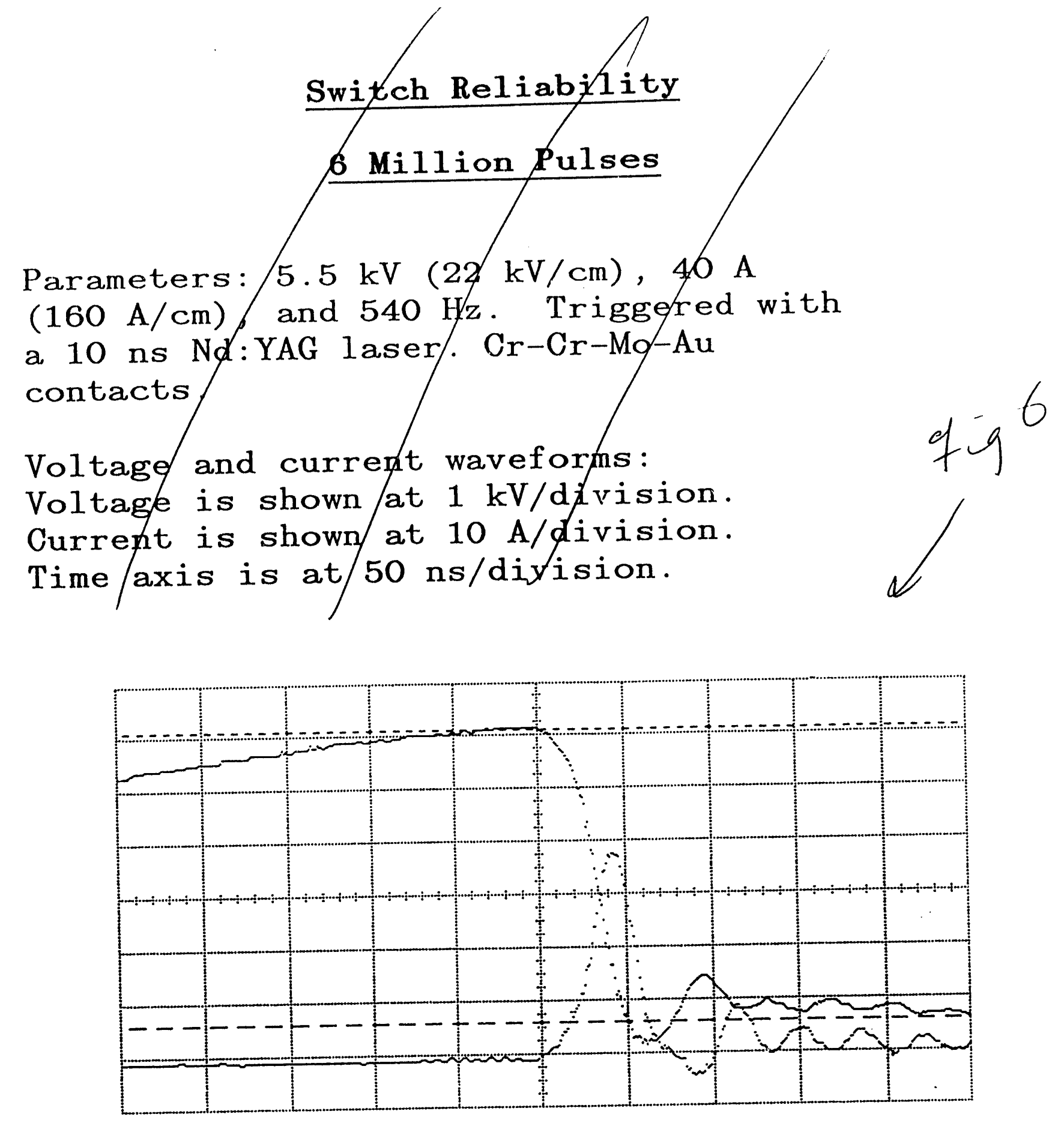


6

.3

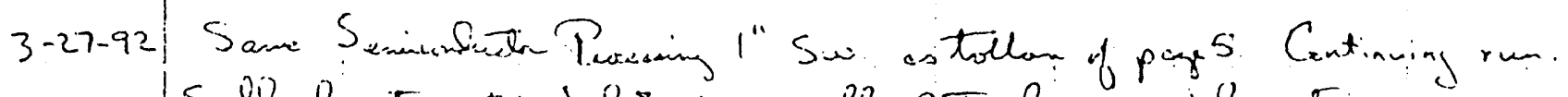

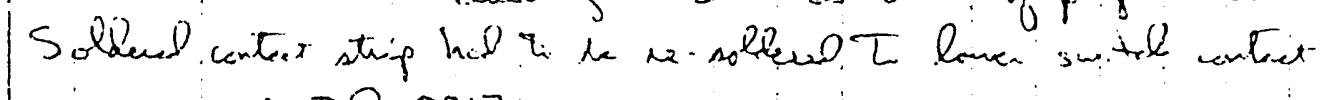
starte 0917.

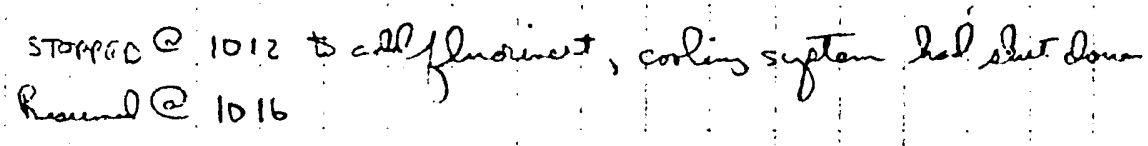

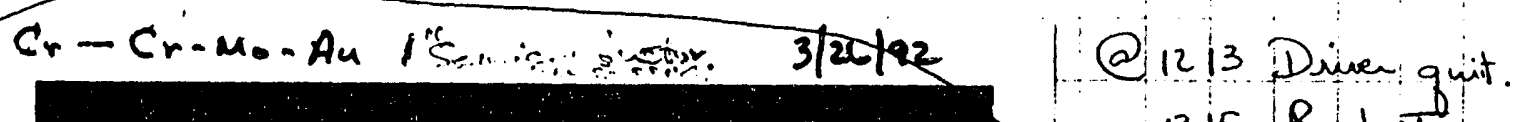

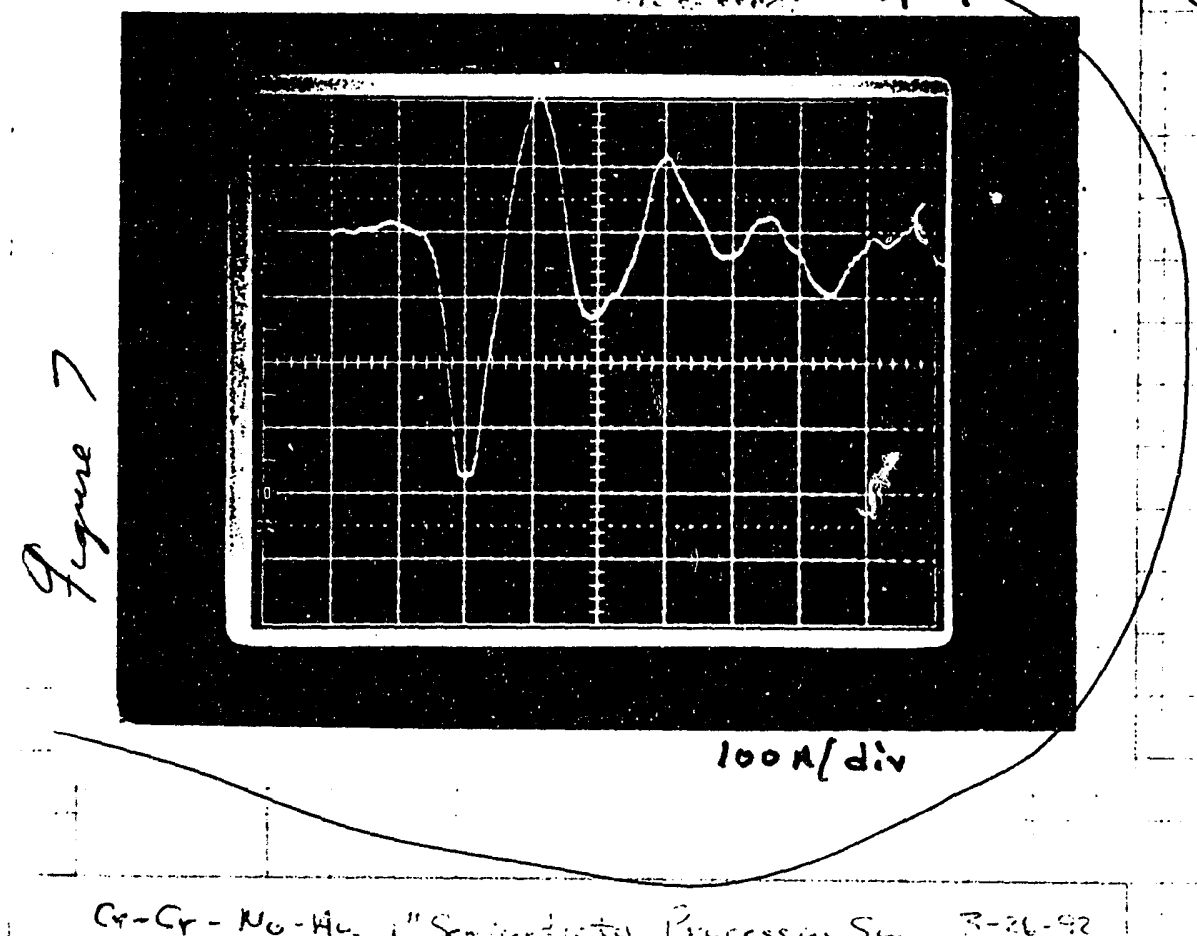
12 is Restau

Quit agaio a 12:20, retestated Agun P $P: 25$

stope $D$ rum $Q 2: 35$ becaine of
diver foiluras (eveng fow minutes)

$$
\begin{aligned}
\text { Tota hum } & =4 \mathrm{hr} .41 \mathrm{~min} \\
& =901 \times 10^{6}
\end{aligned}
$$

BHCK on lad $30 \pi \mathrm{V}$ Hatedrum $2: 25$, amian foilm

$$
\begin{aligned}
\text { Amemale totel } & =5 \mathrm{me} .43 \mathrm{~mm} \\
& =1.11 \times 10^{7}
\end{aligned}
$$




\section{Switch Reliability}

\section{Million Pulses}

Parameters: $8.5 \mathrm{kV}(34 \mathrm{kV} / \mathrm{cm}), 77 \bigcap$

$\left(308 \mathrm{~A} \lambda_{\mathrm{cm}}\right)$, and $540 \mathrm{~Hz}$. Triggered wth

a 10 ns Nd:YAG laser. The switch was

made by SNL's Thin Film and Brazing group.

It had 1 \& of $\mathrm{Al}$ deposited and then heated

at $600 \mathrm{C}$ for $20 \mathrm{minutes}$ followed by

Cr-Mo-Au metallization.

The voltage and current wayeforms shown below were taken at $2 \mathrm{kV} / \mathrm{di}$ and $20 \mathrm{~A} / \mathrm{div}$, and $20 \mathrm{~ns} / \mathrm{div}$. The duration of the current pulse is 17 ns. No degradatipn of the electrical pulse was observed.
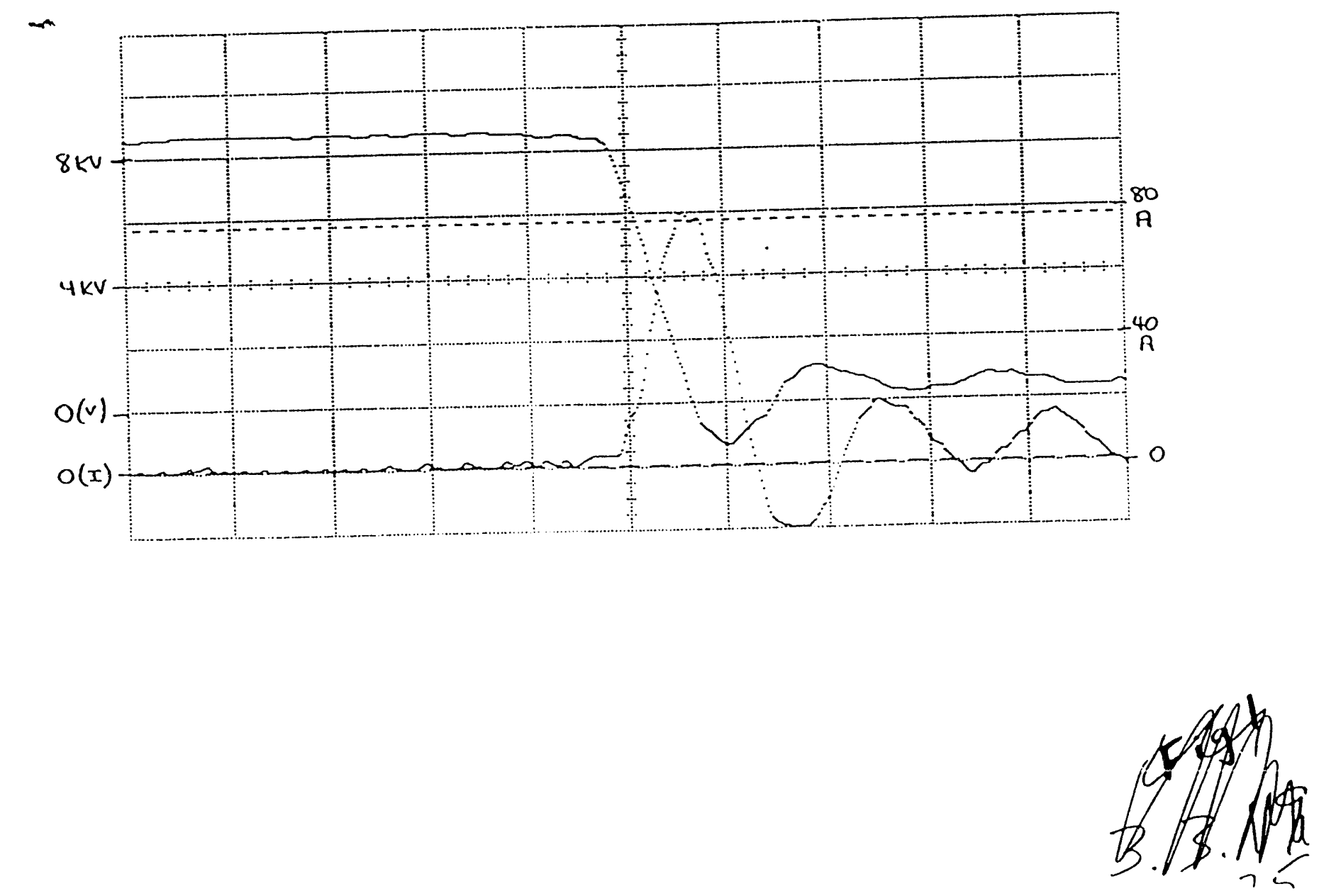
$6-15-92$

DSRI

swit: 2

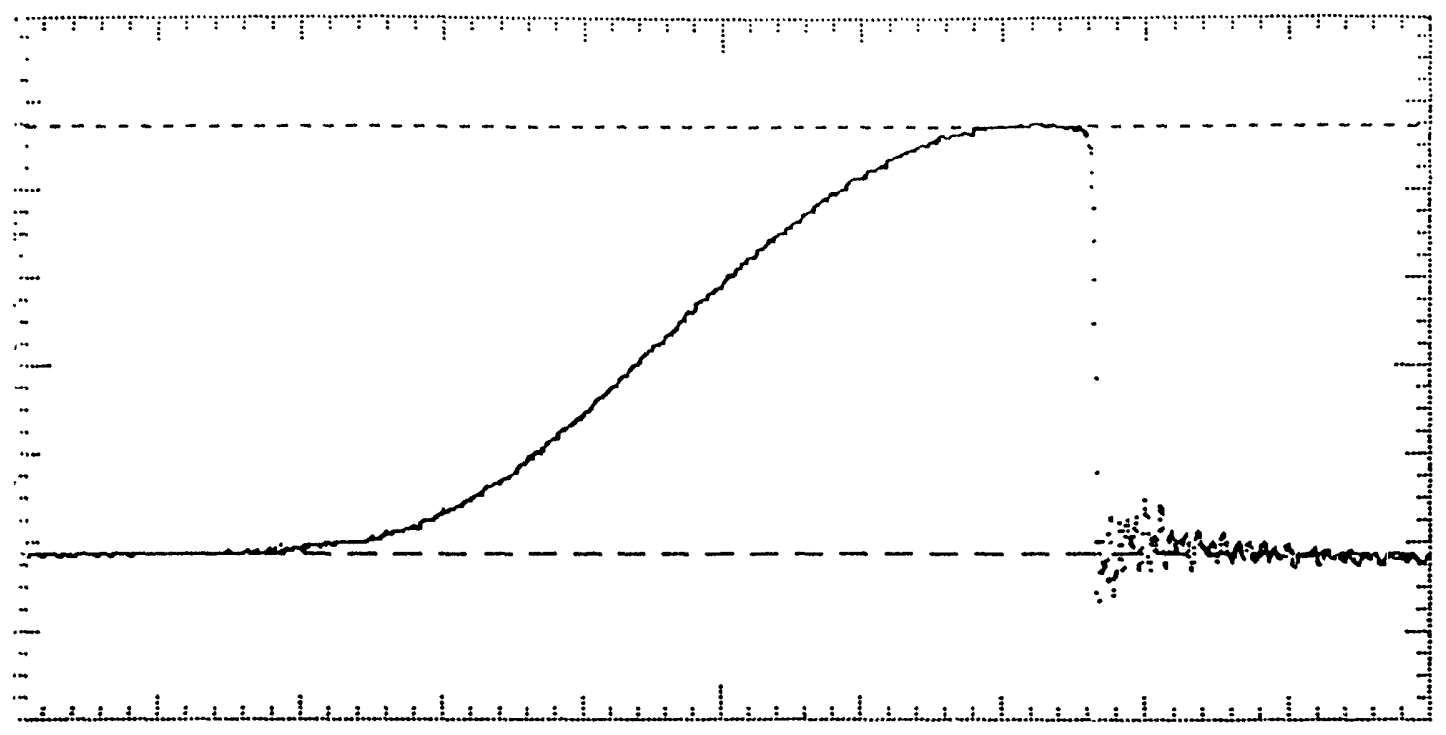

$198.000 \mathrm{~ns}$

1.19800 us

2.19800 us
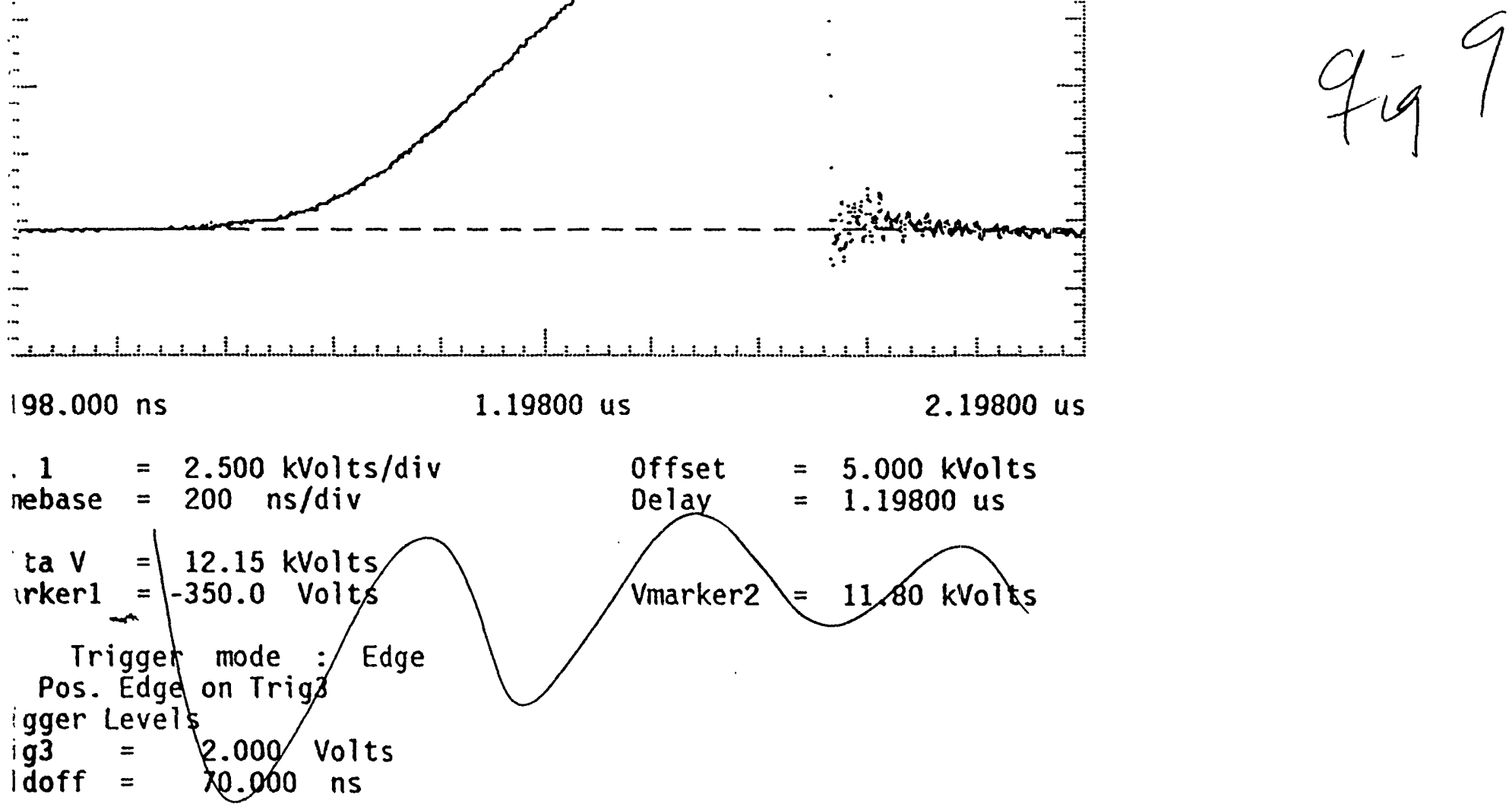

13. 
$6-15-4<$

DSRI

Sw:t:?
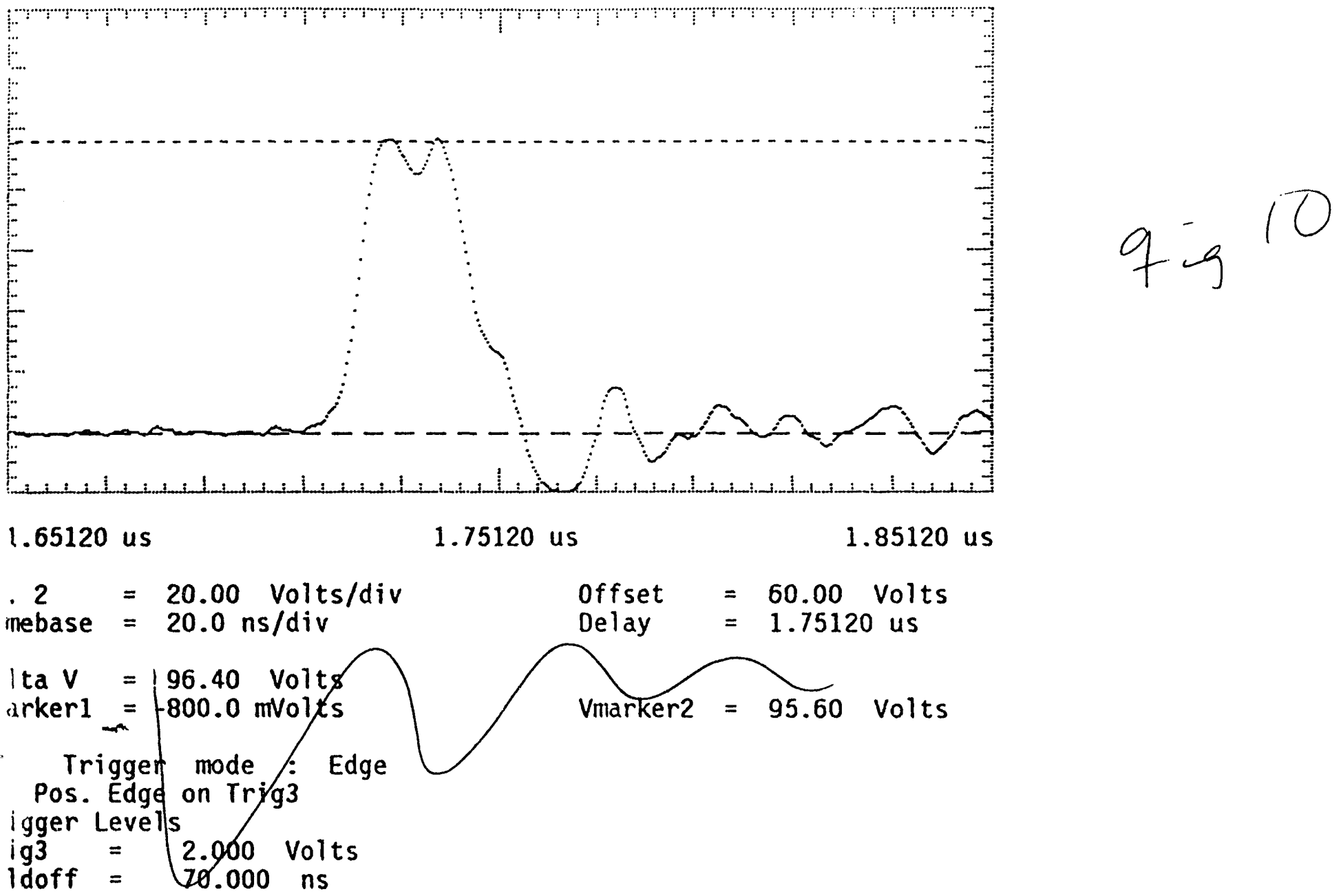

3.3 .3 
Experimental data showing $100 \mathrm{MHz}$ capability

1 ns laser pulse (risetimg)

17 in. long gharge phate (frequency)

$\mathrm{Z} 1=5 \Omega, Z 2=16 \Omega, \mathrm{R}_{\mathrm{s}}=1 \Omega$

VOLTAGE ON LOAD

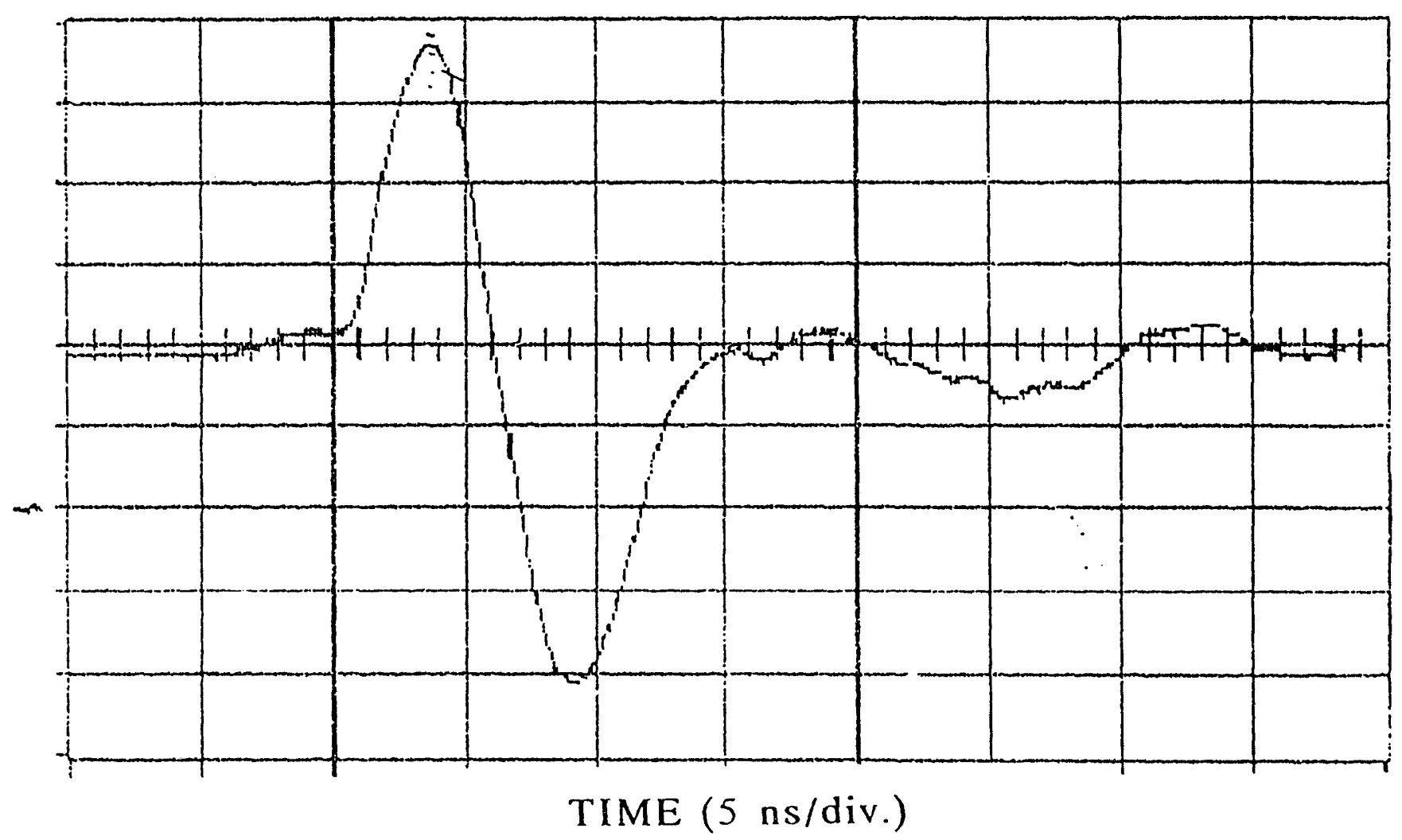

舟2.2. 


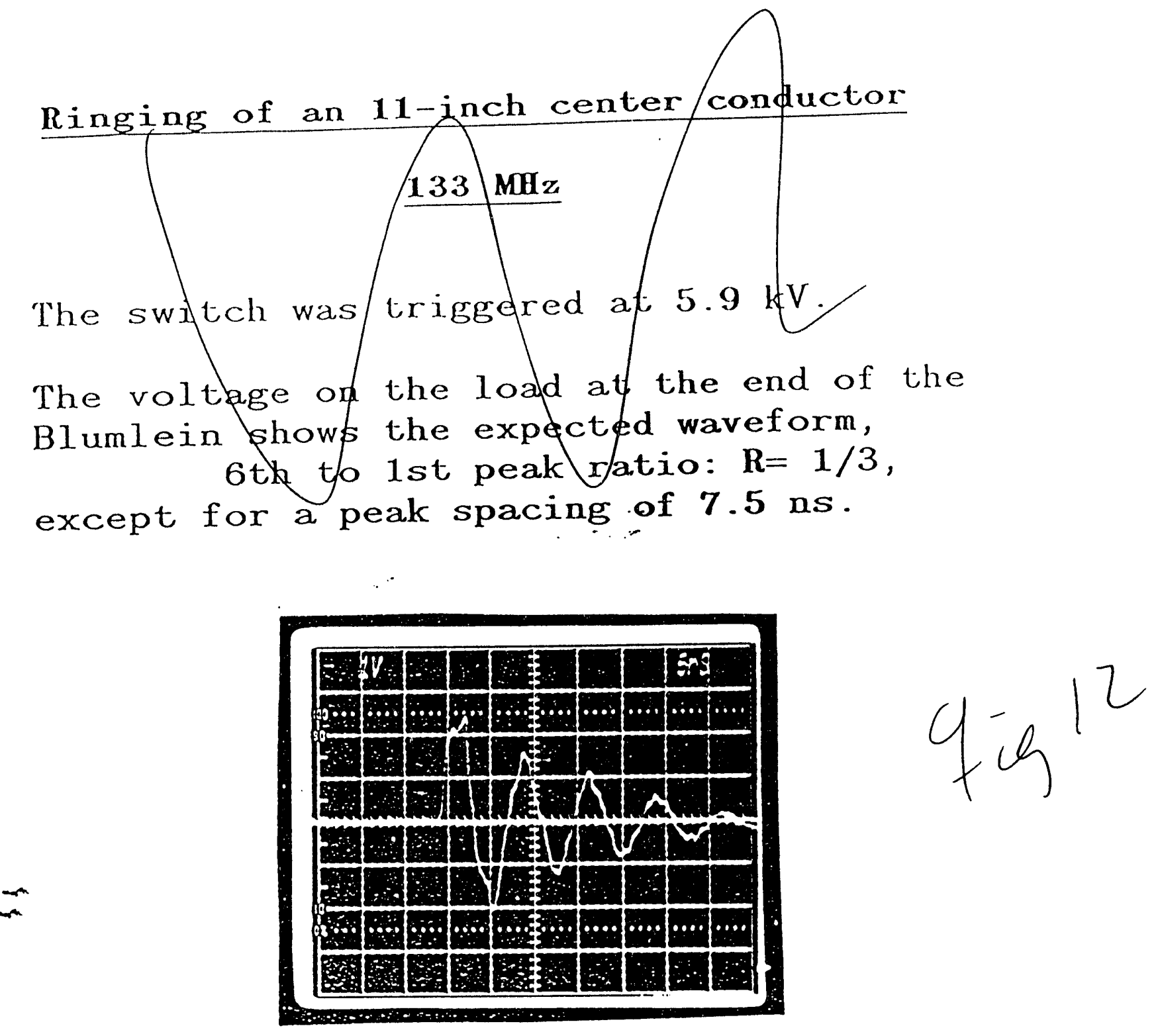

For $\mathrm{Z} 1=16.8 \Omega, \mathrm{Z} 2=141 \Omega$,
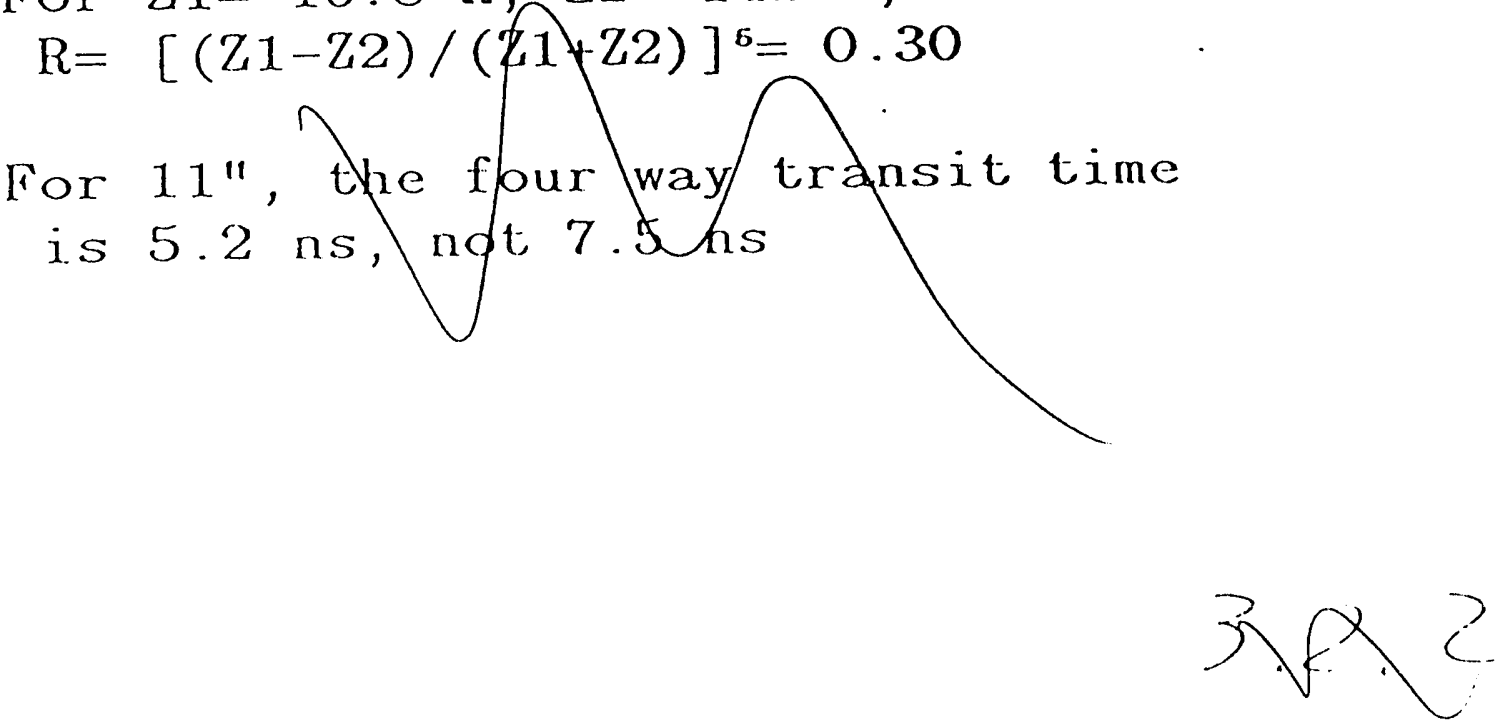
$q=13$

$\begin{aligned} & \frac{1}{x} \\ & r \\ & r\end{aligned} \mid$

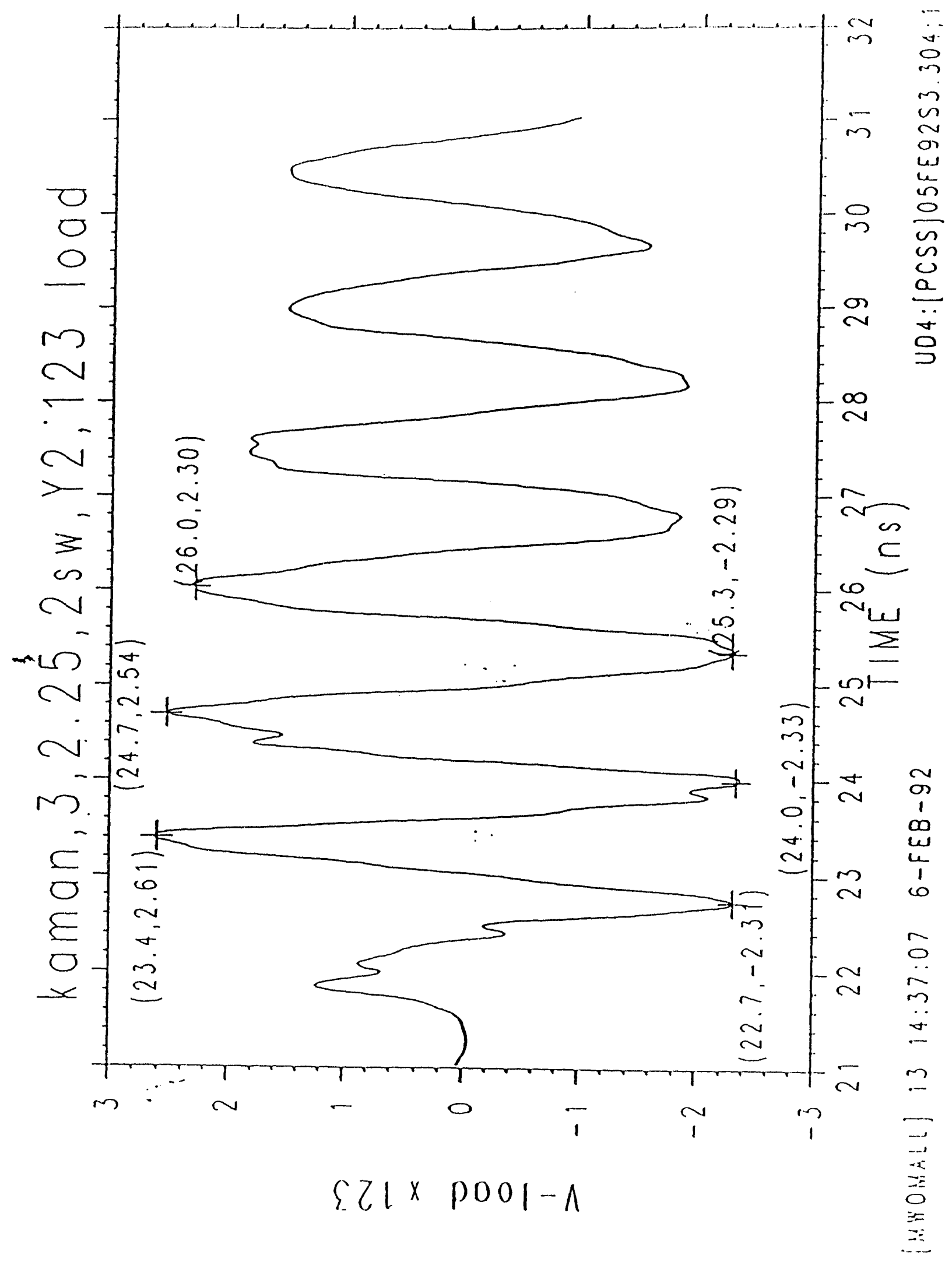



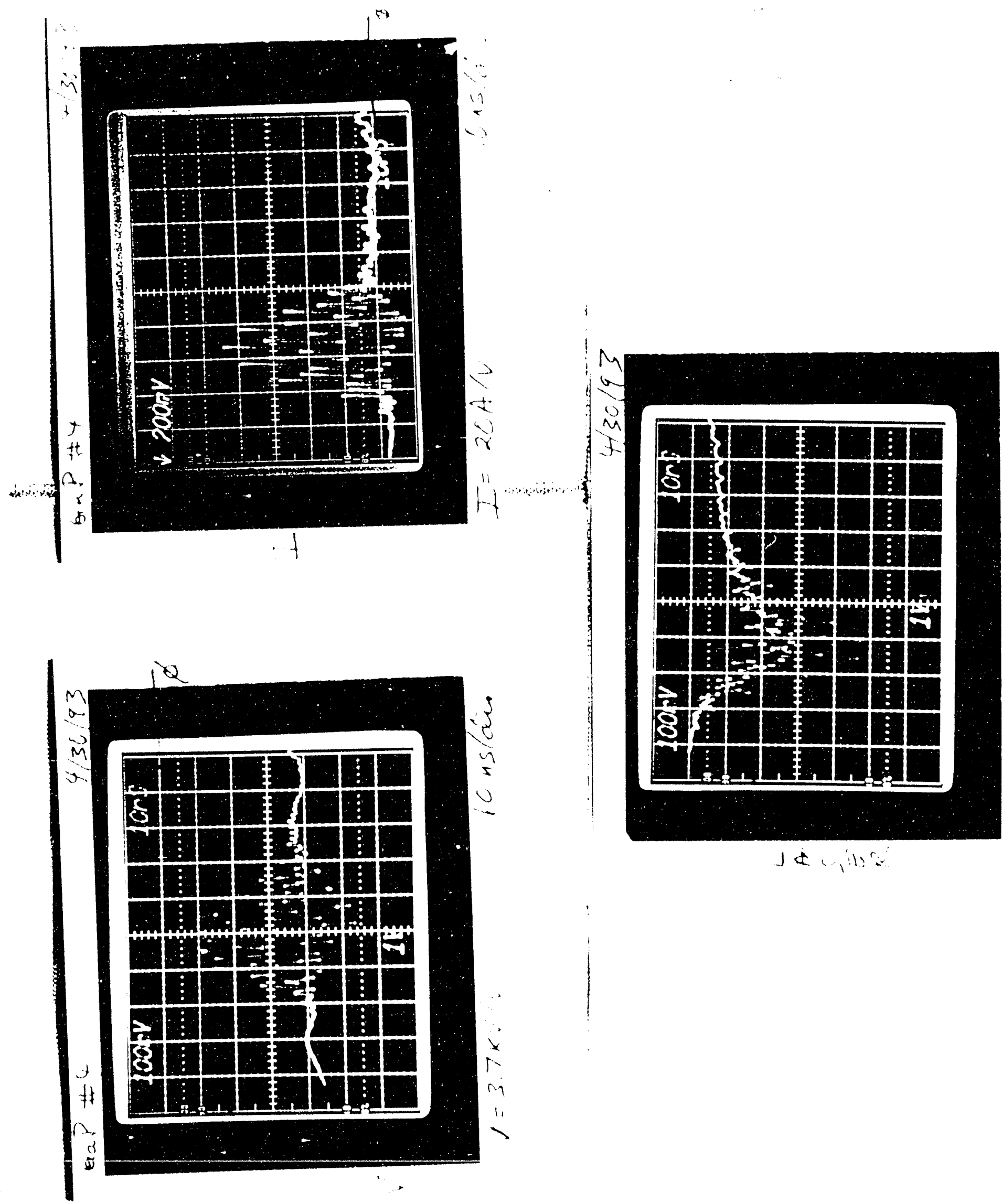

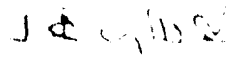



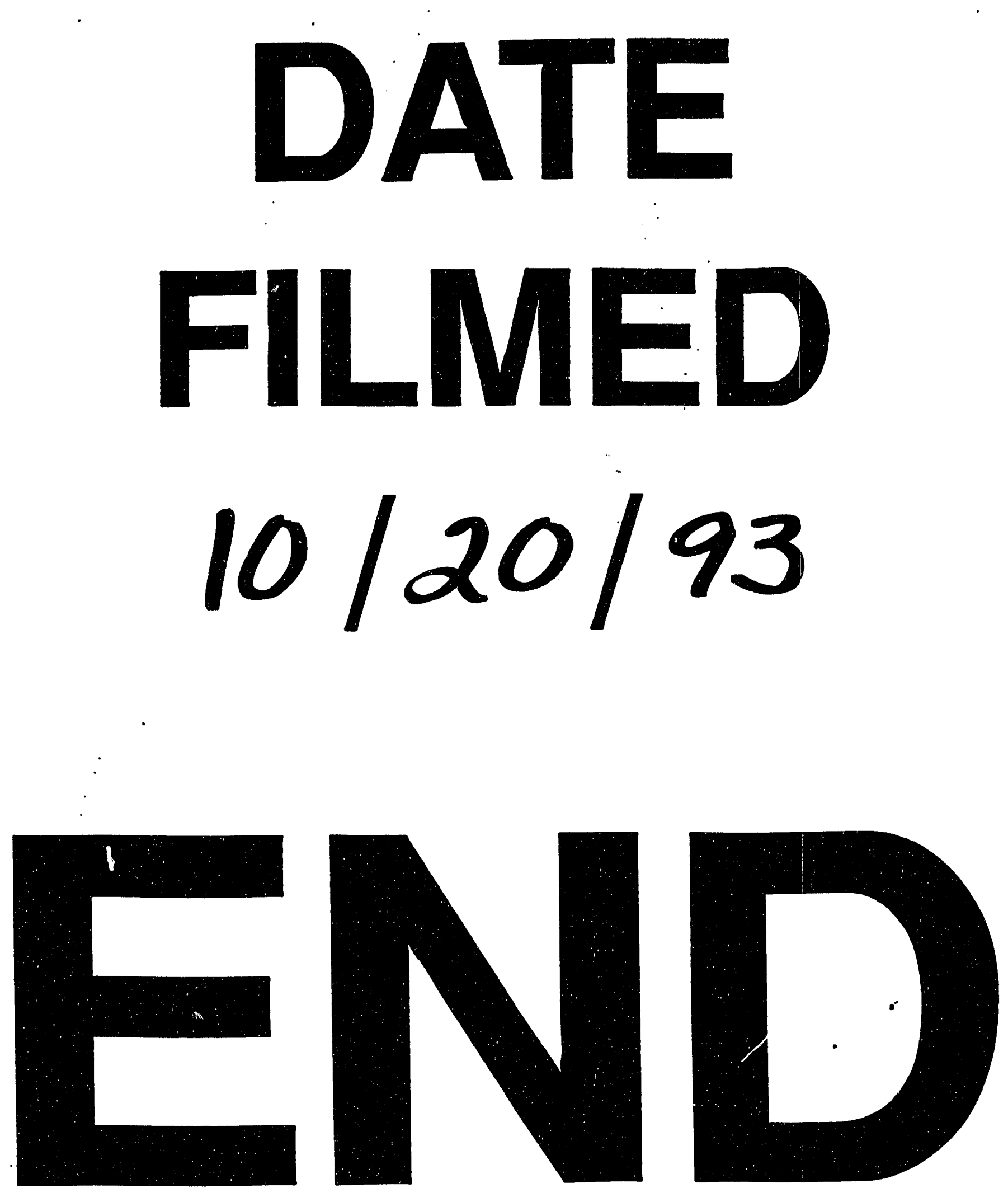
